\title{
The Demographic Window of Opportunity and Economic Growth at Sub-National Level in 91 Developing Countries
}

\author{
Lamar Crombach $^{1}$ iD . Jeroen Smits ${ }^{2}$ D
}

Accepted: 15 September 2021 / Published online: 12 October 2021

(c) The Author(s) 2021

\begin{abstract}
Data for low- and middle- income countries (LMICs) are used to investigate the effect of the demographic transition on economic growth at sub-national level. We introduce a detailed classification of demographic window phases, determine how these phases are distributed among and within LMICs, and analyze the relationship between the demographic window of opportunity (DWO) and economic growth for 1921 urban and rural areas of sub-national regions within 91 LMICs. Many areas in Asia, Latin America and the Middle East have entered the window, but most of Sub-Saharan Africa is still in the traditional or pre-window phase. Our analyses reveal higher growth rates in areas passing through the DWO. Positive growth effects are particularly strong in rural and more educated regions and in countries with lower levels of corruption. Policy measures aimed at effectively using the DW for achieving growth should combine investments in education and rural development with better governance.
\end{abstract}

Keywords Demographic window $\cdot$ Economic growth $\cdot$ Subnational $\cdot$ Fertility reduction . Developing countries · Governance

\section{Introduction}

The role of the population age structure as a potential source for economic growth is gaining importance in the economic literature (e.g. Canning et al., 2015; Groth \& May, 2017; Kelley \& Schmidt, 2005). Fertility reduction may potentially enable a region to have a period of rapid economic growth during the Demographic Window of Opportunity (DWO). The DWO is a period of several decades that countries go through when moving from a situation of high fertility and mortality to low fertility and mortality. This transition

Lamar Crombach

crombach@kof.ethz.ch

Jeroen Smits

jeroen.smits@fm.ru.nl

1 ETH Zürich, KOF Swiss Economic Institute, Konjunkturforschungsstelle, LEE G224

Leonhardstrasse 21, 8092 Zürich, Switzerland

2 Institute for Management Research, Global Data Lab, Radboud University, PO.Box 9108, $6500 \mathrm{HK}$ Nijmegen, The Netherlands 
is generally characterized by a baby boom period, in which (child) mortality is already reduced, but fertility levels are still high. When later fertility also decreases, the baby boom generation moves up in the age distribution and after some time enters the working age population. During this period, more women may enter the labor force as less time needs to be spent on children (Aaronson et al., 2021; Bloom et al., 2009; Cristia, 2008). Given that there are still few elderly - as their generation suffered from higher mortality rates in the past-the region experiences a period in which the working age population is large and the dependent population - the green and the grey-is small. Hence, there is high potential for economic growth, which, if realized, is called the "demographic dividend" (Bloom et al., 2003, 2009; Groth \& May, 2017)

The demographic dividend is often used as an explanation for the rapid economic growth that occurred in East Asian economies in the end of the twentieth century, accounting for as much as one third of the observed national economic growth (Bloom \& Williamson, 1998). The size of this demographic dividend, however, is found to depend on policies regarding labor markets, financial markets, education and health (Bloom et al., 2017; Bloom \& Williamson, 1998; Groth \& May, 2017). Most research tends to focus on the level or growth rate of the dependency ratio, which is measured as the ratio of the share of the dependent population (those aged below 15 and above 65) to the working-age population (those aged 15-65). A low or declining dependency ratio indicates that an area is passing through the DWO.

Due to issues of data availability, the current literature has not yet extensively analyzed the effects of the DWO on economic growth in low-income countries. These countries are often thought of as being stuck in a high-fertility high-mortality situation, i.e. not to have entered the DWO yet (Bloom et al., 2003). Consequently, the empirical basis of the literature has been heavily biased towards growth in middle- income countries with a well-educated workforce and good infrastructure - such as the East Asian Tigers-where the potential for economic growth may have been better than in many of the current low-income countries (Bloom \& Williamson, 1998; Radelet et al., 2001; Williamson, 2013).

The empirical literature has also been very focused on the national level, whereas fertility decline and economic growth may differ substantially between different areas within a country. For instance, cities may show entirely different patterns than rural areas (Sander \& Charles-Edwards, 2017; Williamson, 2013). Furthermore, the national-level fertility transition has been shown to lead to within-country increases in fertility inequality (EloundouEnyegue et al., 2017). By analyzing data at a sub-national level-as is done in the current study - the added variation allows for a more refined analysis of the variables at hand. Indeed, a simple multilevel model of our dependent variable reveals that about $71 \%$ of variation occurs at the sub-national level, while $29 \%$ occurs at the national level.

There are a few published papers that have analyzed the effects of demographic variables at a sub-national level, but they tend to be restricted to regions within a single country. Firstly, Wei and Hao (2010) analyze the impacts of the growth rate and level of the dependency ratio, the total population, and population density, on economic growth in Chinese regions. They also include interactions to analyze under which conditions the dependency ratio is more or less important. Their analyses do not reveal effects of the level of population, urbanization, or the growth rate of the dependency ratio, but they do find significant negative effects of the dependency ratio and population density. Secondly, Baerlocher et al. (2019) estimate the impacts of the participation rate, the working age population, the growth rates of the (working age) population, and the level of and change in the mean years of schooling in micro-regions in Brazil. They find that demographic variables do matter for economic growth, though predominantly through their effect on human capital 
accumulation. Lastly, Kumar (2013) analyzes the effects of the level of, and growth in, the working age share of the population on state-level net GDP per capita in 16 Indian states for the period 1971-2001 and finds significant positive effects of both level and growth, thus pointing towards a favorable effect of the DWO on growth.

The aim of the current paper is threefold. First, we want to find out how the DWO has spread across subnational regions of low and middle-income countries. Second, we aim to determine whether the positive effect of the DWO on economic growth-which has been found for middle-income countries-is also present in low-income countries and in particular at the level of sub-national regions. Third, we want to determine under which circumstances the effect of the DWO is strongest to help policy makers develop contextualized measures that facilitate reaping the demographic dividend in specific areas that have already entered the DWO. Therefore, our central research questions sound:

1. What is the variation in DWO phases at the level of sub-national regions across the developing world?

2. To what extent does the DWO foster economic growth at the sub-national level

3. Which factors are associated with a more effective use of the DWO in terms of economic growth

Our study contributes to the literature in several important ways. It is the first to compare sub-national regions across the developing world in terms of the impact of the DWO on economic growth. We use a database with information for two points in time for 1921 sub-national areas, both urban and rural, spread across 91 different LMICs. Second, a dataset with such richness offers more possibilities for analyzing the role of context factors than the national data on-at most—-some 200 countries that are usually used for growth models. Third, besides average effects, we also study interaction effects. Interaction effects help us to understand how the effect of the DWO depends on specific circumstances. Such insights allow policymakers to implement better-targeted policies. Fourth, economic growth at the sub-national level is indicated by the International Wealth Index (IWI), an asset-based wealth index that is comparable over time and across countries (Smits \& Steendijk, 2015). Analyzing the effects of demographics on the IWI will provide valuable new insights, as IWI measures a household's possession of durables, housing quality and access to basic services and is as such a broader indicator than income or expenditure. As an outcome-based measure, IWI does not need arbitrary adjustments in terms of purchasing power parities, common baskets of goods, or inflation, as is the case with GDP per capita.

The remainder of this paper is structured as follows. The next section will outline the theoretical model, our measure of economic growth and the context factors that are potential determinants of DWO effectiveness. The third section describes the data, the methodology and the control factors. The fourth section outlines the results, and the fifth section will discuss and conclude.

\section{The Theoretical \& Empirical Model}

We begin by defining a standard Cobb-Douglas aggregate production function for region $i$ in country $j$ in the year $T 2$ : 


$$
Y_{i j}^{T 2}=A_{i j}^{T 2} K_{i j}^{T 2^{\alpha}} H_{i j}^{T 2^{1-\alpha}}
$$

where $Y_{i j}$ is GDP, $A_{i j}$ is Total Factor Productivity (TFP), $K_{i j}$ is the capital stock, and $H_{i j}$ is the stock of efficient labor, which consists of the labor force, $L_{i j}$, multiplied by the human capital per worker, $h_{i j}$. Human capital per worker is determined by the years of schooling, $s_{i j}$, and the return to schooling, $\theta$, which is assumed to be constant, in the following functional format:

$$
h_{i j}^{T 2}=e^{s_{i j}^{T 2} \theta}
$$

Dividing output by the labor force allows us to rewrite the production function in per worker terms:

$$
y_{i j}^{T 2}=A_{i j}^{T 2} k_{i j}^{T 2^{\alpha}} h_{i j}^{T 2{ }^{1-\alpha}}
$$

where $y_{i j}$ is GDP per worker, and $k_{i j}$ is the capital stock per worker. To simplify notation, the growth rate is assumed to refer to the growth in period T1-T2. Substituting Eq. 2 into Eq. 3, taking logs and the first difference gives us the following growth rate equation:

$$
g_{i j}^{y}=g_{i j}^{A}+(1-\alpha) \theta \Delta s_{i j}+\alpha g_{i j}^{k}
$$

We follow Baerlocher et al. (2019) by allowing TFP growth to depend on the level of mean years of schooling, with the argument that countries with higher levels of schooling are better able to innovate and generate economic growth. Additionally, countries that are closer to the technological frontier, as proxied by GDP per worker in period T1, will have lower TFP growth (Barro, 1991):

$$
g_{i j}^{A}=\delta+\psi s_{i j}^{T 1}-\mu \ln \left(y_{i j}^{T 1}\right)
$$

In our analysis, we will control for capital stock per worker growth at the national level by using a fixed effects country dummy model. Substituting TFP into the GDP per worker growth equation gives:

$$
g_{i j}^{y}=\delta+\psi s_{i j}^{T 1}-\mu \ln \left(y_{i j}^{T 1}\right)+(1-\alpha) \theta \Delta s_{i j}+\alpha g_{i j}^{k}
$$

To translate the model from GDP per worker to GDP per capita terms, we must adjust the neoclassical model and recognize that a population does not merely consist of workers, but also of dependents:

$$
\left(\frac{Y}{N}\right)_{i j}=\left(\frac{Y}{L}\right)_{i j}\left(\frac{L}{N}\right)_{i j}=\left(\frac{Y}{W A}\right)_{i j}\left(\frac{W A}{N}\right)_{i j}
$$

where $N_{i j}$ is the total population, and $W A_{i j}$ is the working age share of the population, i.e., those aged between 15 and 65 .

Thus, GDP per capita consists of a productivity component, $\frac{Y}{W A}=y$, and a demographic component: $\frac{W A}{N}$. Additionally, for reasons of data availability, we assume $L_{i j}=W A_{i j}$, i.e., full employment. Moreover, as in Wei and Hao (2010), we express the demographic component in terms of the dependency ratio, $D_{i j}$, as opposed to share of the working age population to the total population: $D_{i j}=\frac{N_{i j}-W A_{i j}}{W A_{i j}}$, which gives: 


$$
\left(\frac{Y}{N}\right)_{i j}=\bar{y}_{i j}=\frac{y_{i j}}{1+D_{i j}}
$$

where $\bar{y}_{i j}$ is GDP per capita.

As before, we take logs and the first difference to obtain growth rates. Additionally, we substitute the TFP growth equation into the growth rate of GDP per capita equation. Moreover, note that TFP growth depends on the initial level of income per worker, which we now translate to the initial level of income per capita as well:

$$
\begin{gathered}
g_{i j}^{\bar{y}}=\delta+\psi s_{i j}^{T 1}-\mu \ln \left(\bar{y}_{i j}^{T 1}\right)-\mu \ln \left(1+D_{i j}^{T 1}\right)+\alpha g_{i j}^{k}+ \\
(1-\alpha) \theta \Delta s_{i j}-\Delta \ln \left(1+D_{i j}\right) .
\end{gathered}
$$

Transforming the above equation into an empirical specification with country-specific fixed effects (which absorb national capital stock per worker growth, $g_{i j}^{k}$ ), $\gamma_{j}$, and a random error term at the sub-national level, $\epsilon_{i j}$, gives:

$$
\begin{aligned}
g_{i j}^{\bar{y}}= & \beta_{0}+\beta_{1} s_{i j}^{T 1}+\beta_{2} \ln \left(\bar{y}_{i j}^{T 1}\right)+\beta_{3} \ln \left(1+D_{i j}^{T 1}\right)+ \\
& \beta_{4} \Delta s_{i j}+\beta_{5} \mathrm{~g}^{1+\mathrm{D}_{\mathrm{ij}}}+\gamma_{j}+\in_{i j} .
\end{aligned}
$$

\subsection{Economic Growth at Sub-National Level}

A key issue to overcome is that for most LMICs data on (changes in) GDP per capita at sub-national level is not available. Therefore, we will use (changes in) standard of living of households, as indicated by the International Wealth Index (IWI) (Smits \& Steendijk, 2015) as an alternative. IWI is an asset-based wealth index that measures household wealth in LMICs on the basis of ownership of consumer durables (TV, fridge, phone, car, etc.), quality of housing and access to public services (clean water, electricity). IWI ranks households from 0 to 100 , with 0 meaning none of the durables, bad quality housing and no access to services and 100 meaning all durables, good quality housing and access to high quality services.

Conveniently, one can aggregate IWI from the household level to higher levels, such as the level of sub-national areas and the country level. It then indicates the mean wealth level of households in terms of asset ownership in the sub-national areas or country, while increases in the IWI level of an area over a period of time mean that households in the area were able to increase their stock of assets during that period. An advantage compared to indices based on household income in the context of LMICs is that IWI is less volatile, as it is not very sensitive to income changes due to unstable employment or economic shocks, which are rather prevalent in poor regions (Loayza et al., 2007).

Testing the performance of IWI as indicator of economic growth at the subnational level is not possible, as there is no other indicator available at that level for comparison. However, as Figure S1 in the Supplementary Information shows, at the national level IWI is highly (0.86) correlated with the logarithm of GDP per capita and even more highly (0.92) with the Human Development Index, which suggests that also at subnational level it might be a reasonable indicator of the level of development.

Thus, $I W I_{i j t} \approx \ln \left(y_{i j t}\right)$, i.e., we assume IWI to be an appropriate proxy for the logarithm of GDP per Capita. This changes the specification as follows: 


$$
\begin{aligned}
& g_{i j}^{y}=\ln \left(y_{i j}^{T 2}\right)-\ln \left(y_{i j}^{T 1}\right) \approx \Delta I W I_{i j}=\beta_{0}+\beta_{1} s_{i j}^{T 1}+ \\
& \beta_{2} I W I_{i j}^{T 1}+\beta_{3} \ln \left(1+D_{i j}^{T 1}\right)+\beta_{4} \Delta s_{i j}+\beta_{5} \mathrm{~g}^{1+\mathrm{D}_{\mathrm{ij}}}+\gamma_{j}+\epsilon_{i j} .
\end{aligned}
$$

\subsection{The Role of the Context}

The effect of the DWO on economic growth is not expected to be the same everywhere, but may depend on characteristics of the context in which it takes place (Bloom et al., 2017; Bloom \& Williamson, 1998; Groth \& May, 2017). According to Zuber et al. (2017), DWO effectiveness is influenced by three major factors: (i) job creation, (ii) human capital building and (iii) good governance. A relatively high working age share of the population can only translate into growth if the workers have sufficient employment opportunities. To achieve these opportunities prudent macroeconomic policies are supposed to be required, including a high level of financial market development, a high degree of economic openness and low levels of positive inflation (Collier \& Dollar, 2001; Turbat, 2017). However empirical evidence is mixed. Whereas Easterly (2005) found the effect of good policies on growth to be small and not robust to different econometric specifications, Wei and Hao (2010) present data for China showing the effect of the DWO to be stronger in regions with higher levels of market openness. Regarding the role of human capital building there is not yet much empirical support available. Whereas Kelley and Schmidt (2005) found little effect of education on the size of the DWO effect, other studies (Baerlocher et al., 2019; Crespo Cuaresma et al., 2014) suggest that most gains of the DWO are related to education decisions that are the result of the demographic changes.

The third factor is good governance. We follow Kaufmann et al. (2011) in defining governance as "the traditions and institutions by which authority in a country is exercised". We see governance as good when it is participatory, consensus-oriented, accountable, transparent, responsive, effective and efficient, equitable and inclusive and follows the rule of the law (Zuber et al., 2017). Good governance implies that the government offers high-quality and affordable education and health care to everyone, both of which increase human capital building. Further, the increase in tax income resulting from the relative increase in workers must be used productively. We therefore expect that if the additional resources are wasted on corruption and inefficiencies, the demographic dividend may be substantially harmed.

\section{Data and Methods}

\subsection{Data}

A subnational indicator database was constructed from data of the Database Developing World of the Global Data Lab (GDL) (www.globaldatalab.org), which contains harmonized data for over 30 million persons in 130+ LMICs. The data is derived from Demographic and Health Surveys (DHS, www.dhsprogram.com), Unicef MICS Surveys (mics. unicef.org), IPUMS census data (international.ipums.org), Afrobarometer surveys (www. afrobarometer.org) and several stand-alone surveys (Smits, 2016). Variables obtained from these surveys were aggregated to the level of urban and rural areas of sub-national regions using the regional/provincial codes available in the datasets. In this way, a dataset 
was created with information for two points in time (T1 and T2) for 1921 urban and rural sub-national areas within 91 countries. For each country, data were selected from the last two available surveys that were at least four years apart. Because the surveys were held in different years for the different countries, the time period between the two surveys could vary between four and 16 years. To obtain a simple and comparative measure of economic growth, the average annual change in IWI between the two survey years (T1 and T2) was used. The other change variables in the model reflect the average annual change between times T2 and T2 as well. In this way a dataset was obtained with for each of the 1921 regions the value of the regional characteristics in the first survey (T1) and the annual changes in these characteristics between the first and the second survey (T2).

\subsection{Methods}

To address the fact that the 1921 sub-national regions, which are the units of analysis, are nested within the 91 countries, our regression model included the complete set of fixed effects country dummies. In this way the direct effects of all (measured and unmeasured) country-specific characteristics-including number of sub-national regions and variation in number of years between T1 and T2 - are accounted for, while keeping the possibility to study cross-level interactions with the country-level explanatory variables. Given that within the regions only data for two years was used, a two-period panel data analysis could be performed (Wooldridge, 2013) and no further control for multiple observations within the regions was needed.

The main independent variables are the dependency ratio and the growth rate of the dependency ratio. The dependency ratio is measured as the ratio of the share of the working age population to the share of the dependent population. We define the working age population as all individuals aged between 15 and 64 . We consider all individuals aged below 15 or above 64 as the dependent population.

Besides the dependency ratios, the models contained independent variables at subnational and national level. At subnational level, these variables included the T1 value of IWI, education, the gender difference in education and urbanization. Education was measured as the mean years of schooling of male individuals aged 20 and above in the region. We choose education for the 20 + population because the starting age of schooling is often high in LMICs (Huisman \& Smits, 2009) and individuals under 20 might not yet have completed their education. Gender inequality was measured by the difference between the mean years of schooling for men and for women (education men minus education women). Urbanization was measured by a dummy variable with value zero in rural areas and value one in urban areas. The dummy's value depends on the designation (urban or rural) given by the source surveys, which are based on the official national definition used in the country (United Nations, 2018). Given this rather crude division in only two categories, it may be possible that there are households living in urban areas (e.g., slums) which are less welloff than rural households. The level of IWI at T1 was included as explanatory variable to control for the distance to the technological frontier (convergence) (Barro, 1991).

At the national level, quality of governance, inflation, market openness and financial development were included. To test for good governance, a multidimensional governance index was used, aggregated from the six World Bank worldwide governance indicators (Kaufmann et al., 2011): control of corruption, rule of law, political stability and violence, voice and accountability, government effectiveness and regulatory quality. The scores for these dimensions were all obtained through expert surveys. Each dimension, as well as the 
aggregated governance index, ranges from -2.5 (low) to +2.5 (high). Inflation was taken from the World Development Indicators (World Bank, 2021) and measured as the annual $\%$-change in consumer prices. For market openness, the KOF economic globalization index is used, which ranges from 0 (closed) to 100 (open) and measures the degree of financial and trade openness (Dreher, 2006; Dreher et al., 2008; Gygli et al., 2019). For financial development, the IMF financial development index is used, which ranges from 0 (low development) to 1 (high development) (Svirydzenka, 2016). Missing values on the national variables were addressed using dummy variable adjustment, whereby the mean of the valid cases was imputed and a dummy was added to nullify them (compare Allison, 2002). The national variables were only used to study their interactions with the dependency ratios, as the direct effects of these variables on economic growth are completely covered by the fixed effects approach.

Although the risk of endogeneity bias was restricted because the current growth of the working age population is based on fertility decisions taken in the past, it remains possible that an omitted variable bias in our model was caused by migration. The classic push-pull migration model (Lee, 1966) postulates that migration is caused by the uneven processes of development. Economic opportunities in the form of wage differentials may drive migration streams. Additionally, the demographic transition will lead to a large labor supply (Preston et al., 1989), and mostly in urban areas (Sander \& Charles-Edwards, 2017; Williamson, 2013), which may lead to immigration/emigration if there are many/few opportunities available in the area. Given that migration in low- and middle income areas consists mostly of young adults, as they are the most mobile group (Sander \& CharlesEdwards, 2017), this may lead to a positive relationship between economic development and immigration. As a robustness test, we therefore repeated our analysis with an indicator for migration in the study period. Given that such a measure is not readily available at the subnational level, we developed a proxy of migration as follows:

$$
\text { Migration }_{i j}=\frac{(100+\text { Actual change working age share })}{(100+\text { Expected change working age share })}
$$

Substituting for the actual and expected changes in the working age share gives us:

$$
\text { Migration }=\frac{100+\sum_{k=15}^{64} \Delta \text { share }_{\mathrm{k}}}{100+\sum_{m=15-T}^{15} \text { share }_{m}^{T 1}-\sum_{n=64-T}^{64} \text { share }_{n}^{T 1}-\sum_{p=0}^{T} \Delta \text { share }_{p} \times \frac{\text { WorkAge }^{T 1}}{\text { Elderly }^{T 1}}}
$$

where share is the share of the population of a certain age, $T$ is the total amount of years in the time period of the subnational region, $T 1$ indicates that the value is from the start of the period, WorkAge is the share of the population aged 15-64, and Elderly is the share of the population aged 65 or over. Simply put, the migration measure is the ratio of the actual changes of the 15-64 population shares, divided by the expected changes of the 15-64 population shares based on the T1 population structure, with an adjustment for fertility. This measure is expected to provide a reasonable indication of the role of migration, as the population dynamics in the younger age groups are appropriately included and labor migration is a process that involves mostly young people.

As a second robustness test, we repeated the main analysis, but using data from the period before the T1-T2 setup, i.e., the T0-T1 period. This enables the reader to see to what extent the results depended on the used sample. In a third robustness test we perform the same analysis using data at the national level, but split up into a rural and urban part to 
maintain comparability with the other analyses. This setup may highlight the importance of using sub-national data to capture context factors that are important during the DWO.

\section{Results}

\subsection{Descriptive Analyses}

Before the discussion of the regression results, this section offers a descriptive perspective on the status of the DWO across the developing world. Because a detailed classification scheme for the DWO phase of a region was lacking, we use a new one that takes a simpler scheme used by the United Nations (UN) Population Division (UN, 2004, p. 70) as a starting point (compare Smits, 2016). The UN scheme distinguishes three DW phases: a pre-window phase with 30 or more percent of the population under 15 years old, a window phase with less than 30 percent under 15 years old and less than 15 percent above 64 years old, and a post-window phase with 15 or more percent above 64 years old. To get a more refined picture of the window, the GDL added a traditional phase, for countries that show hardly any sign of fertility reduction, and further subdivided the first two phases of the UN classification to obtain the following scheme:

1. Traditional phase ( $>40 \%$ under 15 and $<15 \%$ over 64$)$,

2. Pre-window phase (30-40\% under 15 and $<15 \%$ over 64$)$,

3. Early-window phase $(25-30 \%$ under 15 and $<15 \%$ over 64$)$,

4. Mid-window phase $(20-25 \%$ under 15 and $<15 \%$ over 64$)$,

5. Late-window phase $(<20 \%$ under 15 and $<15 \%$ over 64$)$,

6 . Post-window phase ( $>15 \%$ over 64$)$.

Figure 1 displays the DWO phase for 1921 subnational regions in 91 LMICs. The map reveals a substantial amount of variation in terms of DW phases both between and within LMICs. China is the only country where some sub-national regions are already in the postwindow phase, while its northern neighbor, Mongolia, is mostly in the pre-window phase.

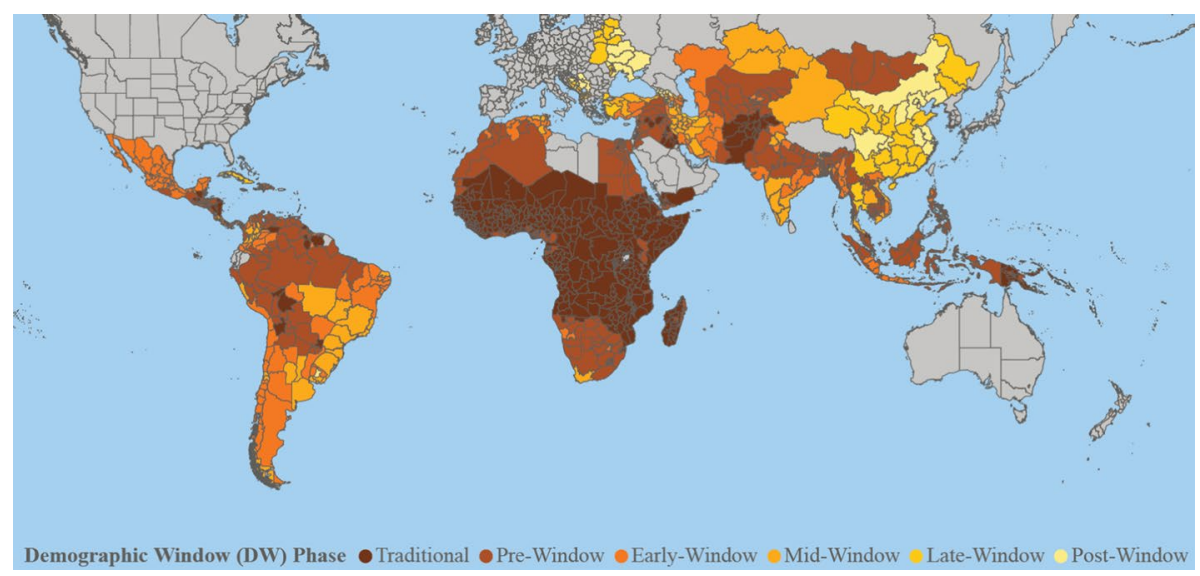

Fig. 1 Demographic Window Phases across the developing world. Source: Global Data Lab 
India, on the other hand, has a clear north-south divide. While most of the south is in the mid-window phase, the north is still mostly in the pre-window phase. The MENA region shows a diverse pattern, with many regions in Turkey, Tunisia, and Iran already in the early-window phase, while other countries are still in the pre-window or traditional phases. In South America, countries such as Brazil and Argentina are in the lead in terms of the demographic transition.

In Sub-Saharan Africa (SSA), the picture is rather different from the other continents, with much less variation between countries and regions. Although a few areas, mostly in the south, appear to be past the traditional or pre-window phases, the majority of the central African region remains in the traditional phase. In Fig. 2, which zooms in on the SSA region, the picture remains more or less the same as well, with only a limited number of areas in the South, around the Gulf of Guinea and at a few other places that are in a later stage. These areas largely coincide with the countries called 'vanguard countries' by Eloundou-Enyegue and Hirschl (2017), i.e. those countries that started the earliest with the DWO as measured by having a Total Fertility Rate (TFR) of less than 3.5.

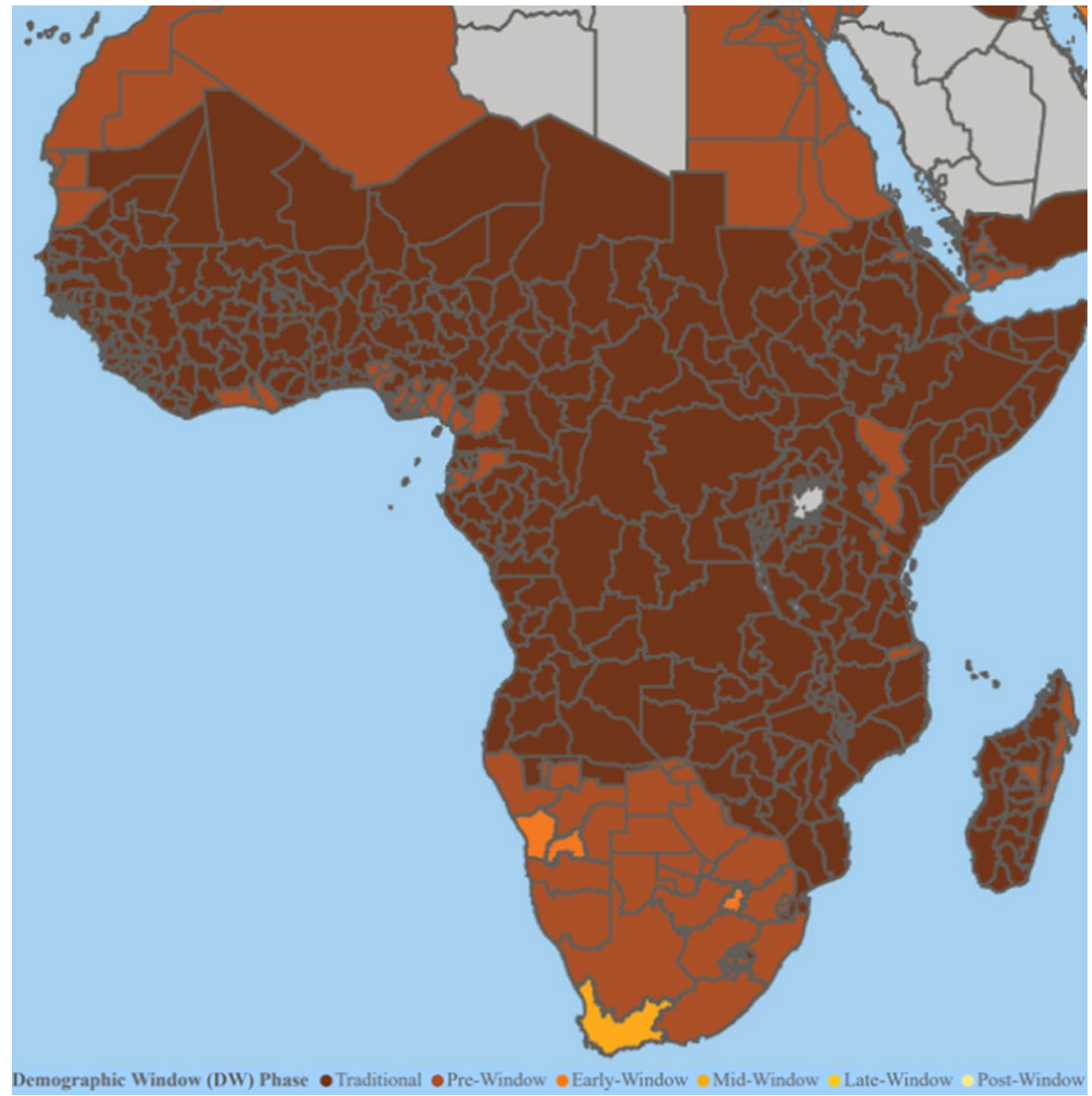

Fig. 2 Demographic Window Phases across the African continent. Source: Global Data Lab 
To have an even more refined view of the demographics in SSA, Table 1 displays the SSA countries that, at the national level, are not in the traditional phase anymore. The tourist destinations Mauritius (Phase 5) and Cape Verde (Phase 3) turn out to be the most developed in this respect, while Gabon and the five most southern countries are in phase 2. Thus, in SSA, only eight countries are not in the traditional phase when countries as a whole are considered.

However, demographic developments are generally not homogeneously spread within countries. As was already clear from Fig. 1, in many countries there is substantial subnational variation in terms of DW phases. Given that fertility reduction tends to start earlier in urban than in rural areas (Easterlin, 1971), we would expect the first signs of an emerging window to be found in the cities (Williamson, 2013). For the SSA region, variation in fertility has already been observed for countries like Nigeria and the Democratic Republic of Congo, where fertility is substantially lower in more urban and capital areas than in rural and remote areas of the countries (Jimenez \& Pate, 2017; Shapiro et al., 2017). To see whether more of such signs can be discerned in the SSA region, Table 1 also displays the DW phases of the SSA countries with an urban DW phase above phase one (excluding Mauritius and Cape Verde for which no sub-national DW data were available). In 24 countries, the urban areas are in phase two, and in two countries, Lesotho, and South Africa, already in phase three.

To look even more in depth, Table 2 displays the urban areas of sub-national regions that have a DW phase of three or over (i.e., the urban areas that have surpassed the prewindow phase and have thus actually entered the window). It shows that the DW is opening in more places than one would expect based on Table 1. For instance, while Botswana as a whole is only in the second phase of the DWO and its urban areas as well, the urban area of one of its regions-South-East-is already in the fourth phase, i.e., the mid-window phase. Lastly, while Ethiopia as a whole is in phase one and its urban areas on average in phase two, the country's capital Addis Ababa is already in phase four.

Table 1 Demographic window phases of SSA countries with national or urban areas that are not in the traditional demographic window phase

\begin{tabular}{llllll}
\hline Country & National & Urban & Country & National & Urban \\
\hline Mauritius & 5 & - & Eritrea & 1 & 2 \\
Cape Verde & 3 & - & Ethiopia & 1 & 2 \\
Botswana & 2 & 2 & Ghana & 1 & 2 \\
Eswatini & 2 & 2 & Guinea Bissau & 1 & 2 \\
Gabon & 2 & 2 & Kenya & 1 & 2 \\
Lesotho & 2 & 3 & Madagascar & 1 & 2 \\
Namibia & 2 & 2 & Mauritania & 1 & 2 \\
South Africa & 2 & 3 & Malawi & 1 & 2 \\
Burundi & 1 & 2 & Rwanda & 1 & 2 \\
Burkina Faso & 1 & 2 & Senegal & 1 & 2 \\
Cote D'Ivoire & 1 & 2 & Sierra Leone & 1 & 2 \\
Cameroon & 1 & 2 & Togo & 1 & 2 \\
Comoros & 1 & 2 & Tanzania & 1 & 2 \\
Congo Brazzaville & 1 & 2 & Zimbabwe & 1 & 2 \\
\hline
\end{tabular}


Table 2 Demographic window phases of urban areas of subnational regions in SSA that have entered the DWO (phase 3 or higher)

\begin{tabular}{llllll}
\hline Country & Urban Regions & Phase & Country & Urban Regions & Phase \\
\hline Ethiopia & Addis Ababa & 4 & Lesotho & Leribe & 3 \\
Botswana & South-East & 4 & Lesotho & Berea & 3 \\
South Africa & Western Cape & 3 & Lesotho & Maseru & 3 \\
South Africa & KwaZulu Natal & 3 & Lesotho & Mafeteng & 3 \\
South Africa & Eastern Cape & 3 & Lesotho & Quthing & 3 \\
South Africa & North West & 3 & Namibia & Erongo & 3 \\
South Africa & Gauteng & 3 & Namibia & Khomas & 3 \\
South Africa & Mpumalanga & 3 & Namibia & Ohangwena & 3 \\
South Africa & Northern Province & 3 & Eswatini & Hhohho & 3 \\
Ethiopia & Oromiya & 3 & Eswatini & Lubombo & 3 \\
Botswana & North-East & 3 & & & \\
\hline
\end{tabular}

The different countries and the time periods used in the analyses are shown in the online Supplementary Information (SI). In terms of the descriptive statistics, Table 3 shows there is substantial variation in terms of all variables. T1 IWI, i.e., the value for IWI at the start of the analyzed period, ranges from 1.82 to 94.99 . Thus, there are regions where the average household in the first year owned almost none of the assets that are included in the index, while there are also regions in which households owned almost all assets in the first year. In terms of economic growth, there is also substantial variation, as the lowest average yearly change between T1 and T2 in IWI was -3.96 while the largest average yearly change was 5.72. In terms of male education, average mean years of schooling ranged from 0.23 years to 13.40 years. Regarding gender inequality in education, there are regions where men, on average, went to school 5.77 years longer than women, while there are also regions where women, on average, went to school 2.08 years longer than men.

Table 3 Sample Descriptive Statistics

\begin{tabular}{lcccc}
\hline Variable & Mean & St. Deviation & Minimum & Maximum \\
\hline$\Delta$ IWI & 0.994 & 1.103 & -3.964 & 5.723 \\
T1 IWI & 49.91 & 24.27 & 1.82 & 94.99 \\
T1 Dependency Ratio (\%) & 77.90 & 25.37 & 15.30 & 204.60 \\
Growth Dependency Ratio (\%) & -0.20 & 2.45 & -7.96 & 17.95 \\
T1 Male Schooling (Years) & 6.80 & 2.80 & 0.23 & 13.40 \\
$\Delta$ Male Schooling (Years) & 0.10 & 0.15 & -0.82 & 0.89 \\
T1 Male-Female Schooling (Years) & 1.29 & 1.17 & -2.08 & 5.77 \\
$\Delta$ Male-Female Schooling (Years) & -0.009 & 0.106 & -0.448 & 0.818 \\
Governance & -0.638 & 0.499 & -2.220 & 0.707 \\
Financial Development & 0.208 & 0.129 & 0.026 & 0.647 \\
Migration & 0.888 & 0.049 & 0.668 & 1.100 \\
\hline
\end{tabular}




\subsection{Multivariate Analyses}

Tables 4 and 5 show the results of our multivariate analyses. Model 1 in Table 4 includes all sub-national determinants of the change in IWI. The demographic window effect is clearly present, as the results show that both a lower T1 dependency ratio and a lower growth rate of the dependency ratio are associated with a significant increase in IWI growth.

Regarding the other factors in the model, we observe the expected negative effect of IWI at T1 on the growth in IWI. IWI growth is also higher in urban regions, in regions with higher levels of male schooling, in regions with a higher growth in male schooling, in regions with a smaller gender difference in schooling and in regions where the gender difference in schooling is decreasing.

Model 2 in Table 4 introduces all significant interaction terms between the independent variables and the dependency ratios and between the subnational control factors themselves. Regarding the main effects of the independent variable, we observe little

Table 4 Coefficients of fixed effects regression models of selected independent variables on economic growth in subnational regions of LMICs

\begin{tabular}{|c|c|c|c|c|}
\hline & Model 1 & & Model 2 & \\
\hline Dependency ratios & Beta $(\beta)$ & T-value & Beta $(\beta)$ & T-value \\
\hline T1 Dependency Ratio (log) & $-3.107^{* * *}$ & $(-9.61)$ & $-2.572^{* * *}$ & $(-7.97)$ \\
\hline Growth Dependency Ratio & $-0.176^{* * *}$ & $(-7.79)$ & $-0.144^{* * *}$ & $(-6.17)$ \\
\hline \multicolumn{5}{|l|}{ Control factors } \\
\hline T1 IWI & $-0.0503^{* * *}$ & $(-21.71)$ & $-0.0539^{* * *}$ & $(-23.69)$ \\
\hline T1 IWI $*$ T1 IWI & & & $-0.000299^{* * *}$ & $(-4.88)$ \\
\hline Urban & $0.145^{* *}$ & $(2.90)$ & $0.213^{* * *}$ & $(4.31)$ \\
\hline T1 Male Education & $0.0861^{* * *}$ & $(4.61)$ & $0.0898^{* * * *}$ & $(4.88)$ \\
\hline T1 Male-Female Education & $-0.0702^{*}$ & $(-2.54)$ & $-0.153^{* * *}$ & $(-5.24)$ \\
\hline$\Delta$ Male Education & $4.098^{* * *}$ & $(26.49)$ & $4.300^{* * *}$ & $(27.40)$ \\
\hline$\Delta$ Male-Female Education & $-2.868^{* * *}$ & $(-12.09)$ & $-3.294^{* * *}$ & $(-13.81)$ \\
\hline \multicolumn{5}{|l|}{ Interactions with dependency ratios } \\
\hline T1 Dependency Ratio $(\log ) *$ T1 Male Education & & & $-0.461^{* * *}$ & $(-5.11)$ \\
\hline T1 Dependency Ratio $(\log ) *$ Urban & & & $1.429^{* * *}$ & $(4.00)$ \\
\hline Growth Dependency Ratio * Urban & & & $0.0845^{*}$ & $(2.27)$ \\
\hline Growth Dependency Ratio * T1 IWI & & & $-0.00244^{*}$ & $(-2.33)$ \\
\hline Growth Dependency Ratio * T1 Governance & & & $-0.135^{* * *}$ & $(-3.44)$ \\
\hline Growth Dependency Ratio * T1 Financial Development & & & $0.514^{*}$ & $(2.29)$ \\
\hline \multicolumn{5}{|l|}{ Interactions among sub-national control factors } \\
\hline T1 IWI * T1 Male Education & & & $-0.00213^{* *}$ & $(-3.12)$ \\
\hline $\mathrm{T} 1 \mathrm{IWI} * \Delta$ Male Education & & & $-0.0187^{* *}$ & $(-3.03)$ \\
\hline Urban * T1 Male-Female Education & & & $-0.109^{* * *}$ & $(-4.02)$ \\
\hline T1 Male Education $* \Delta$ Male-Female Education & & & $0.264^{* * *}$ & $(4.04)$ \\
\hline T1 Male-Female Education $* \Delta$ Male Education & & & $-0.374^{* * *}$ & $(-4.68)$ \\
\hline \# Observations & 1,921 & & 1,921 & \\
\hline \# Countries & 91 & & 91 & \\
\hline
\end{tabular}

$t$ statistics in parentheses. ${ }^{*} p<0.05,{ }^{*} * p<0.01, * * * p<0.001$ 
Table 5 Fixed effects regression models of effects of the demographic window phases on economic growth in subnational regions of LMICs

(1)

Model 1

\begin{tabular}{lll}
\hline & Beta $(\beta)$ & T-value \\
Demographic window phases & & \\
(2) Pre-window phase & $0.271^{* * *}$ & $(5.09)$ \\
(3) Early-window phase & $0.267^{* *}$ & $(3.21)$ \\
(4) Mid-window phase & $0.252^{*}$ & $(2.09)$ \\
(5) Late-window phase & 0.0476 & $(0.28)$ \\
(6) Post-window phase & -0.0422 & $(-0.22)$ \\
Control factors & & \\
T1 IWI & $-0.0454^{* * *}$ & $(-19.80)$ \\
Urban & $0.131^{*}$ & $(2.56)$ \\
T1 Male Education & $0.149^{* * *}$ & $(8.41)$ \\
T1 Male-Female Education & $-0.101^{* * *}$ & $(-3.59)$ \\
$\Delta$ Male Education & $4.686^{* * *}$ & $(33.66)$ \\
$\Delta$ Male-Female Education & $-3.239^{* * *}$ & $(-13.68)$ \\
\# Observations & 1,921 & \\
\# Countries & 91 & \\
\hline
\end{tabular}

$t$ statistics in parentheses. $* p<0.05, * * p<0.01, * * * p<0.001$

change. The coefficients of the T1 dependency ratio and of the growth of the dependency ratio remain highly significant and negative, thus again confirming that both a lower dependency ratio and a decreasing dependency ratio are associated with significantly more economic growth.

The interaction coefficients show that the effect of the dependency ratio is conditional on the level of urbanization of the region. Both the T1 dependency ratio and the growth rate of the dependency ratio have a significantly weaker negative effect in urban regions. Hence the DWO effect is, on average, stronger in rural areas. Regarding education, we observe that declines in the $\mathrm{T} 1$ dependency ratio are more effective in increasing growth when the region has high levels of initial male education (human capital stock). In terms of the growth rate of the dependency ratio, we find that its effect is larger in countries with a stronger institutional environment. In unreported analyses, we find that the governance effect predominantly occurs due to variation in the control of corruption component of the Worldwide Governance Indicators and that no interaction of the other components is significant if control of corruption is included. The interaction coefficient of control of corruption is -0.165 and has a t-value of -4.02 . Somewhat surprisingly, we find that the DWO is more effective in regions with less financial development. This suggests that the DWO might be able to create growth even in regions where factors usually associated with job creation (inflation reduction, financial market development, economic openness) are not (yet) well developed.

Our effects are quantitatively important. For instance, a one standard deviation decrease in the $\mathrm{T} 1$ dependency ratio or the growth in the dependency ratio, leads to a 0.36 or 0.15 standard deviation increase in IWI growth for an average region, respectively. The effect of the $\mathrm{T} 1$ dependency ratio is $50 \%$ stronger than the average effect in regions with one standard deviation of $\mathrm{T} 1$ male education above the average, and $28 \%$ 
weaker than the average effect in urban regions. Further, the effect of growth in the dependency ratio is $47 \%$ stronger in regions with one standard deviation of governance above the average.

The negative effect of IWI at T1 remains in the interaction model, but it is now nonlinear, and conditional on the level and change in (male) schooling. The larger the level of or increase in schooling, the stronger the T1 IWI effect. Conversely, one could argue that (faster) increases in the level of schooling have a stronger effect in regions with an initially lower level of development.

To get a more detailed picture of the relationship between the DWO and economic growth, in Table 5 the dependency ratios are replaced by the T1 DW phases. With regard to the other independent variables, the model is equal to Model 1 of Table 4 . The table shows that regions in the second, third and fourth DW phase have significant higher growth rates than the traditional DW phase. This effect is still positive but not significant in the late window phase. In the postwindow phase, it has disappeared completely. As such, the results are in line with the idea that the DWO is a temporary period of higher growth. However, given that the effect is already positive in the pre-window phase and not significant anymore in the late window phase, it seems that the positive effects of a decrease of the dependency ratio can already be felt earlier than has been assumed before (e.g., UN, 2004).

\subsection{Robustness Tests}

The models presented in Table S1 in the Supplementary Materials use the same strategy as those in Table 4, but with different data, estimation techniques or variables. The first column shows the coefficients of the model that controls for migration flows within and between regions. Although the coefficient of the migration variable has the expected positive sign, it is not significant at the conventional confidence level of $95 \%$. All other effects are robust to the inclusion of the proxy for migratory flows. In the T0-T1 column, we use the same strategy as before, but we go back one period in time for all countries where another period of at least four years is available. Thus, instead of explaining the variation in changes in the period between times $\mathrm{T} 1$ and $\mathrm{T} 2$, we now analyze the variation in changes in the period between times $\mathrm{T} 0$ and $\mathrm{T} 1$. This is possible for 1254 regions in 55 countries. The effects of the main variables - dependency ratio and change in dependency ratio - remain significant. We also note that the main effects of the DWO increase in size, while only the interaction between the change in the dependency ratio and T1 governance remains significant. Of the other variables, we observe that the $\mathrm{T} 1$ difference between male and female schooling, and some interactions, lose their significance. The third column shows the results we would have obtained if we only had data at the national level, but with a split between urban/rural regions. This analysis is based on data for 91 countries and 182 observations in total. In this setup, the $\mathrm{T} 1$ dependency ratio and the change in the dependency ratio are no longer significant. In addition, many of the control factors and all interactions lose their significance. This highlights the added value of our sub-national approach.

Overall, we conclude that our main findings regarding DWO effectiveness are robust to the inclusion of migratory flows and the use of older survey data. Nevertheless, T1 Governance is the only significant determinants of DWO effectiveness in the T0-T1 setup. Further, we highlight that sub-national data is better able to capture context-specific effects than national data. 


\section{Discussion and Conclusion}

In this study, we aim to contribute to the existing literature on the effects of the DWO on economic growth, by studying this relationship at the level of sub-national regions within LMICs. Our data reveal that there is substantial variation in terms of the DWO at the sub-national level, not only in middle-income countries, but also in low-income countries. As such, significant informative value can be gained from analyzing the effect of population age-structures on economic growth at a sub-national level in LMICs.

To achieve this, we created a dataset of 1921 regions in 91 LMICs and we used a fixed effects country dummy model to explain the variation in growth (measured by the International Wealth Index) among these regions. The results indicate that the DWO is indeed a statistical reality. Economic growth was largest in regions with a lower dependency ratio, as well as in regions where the dependency ratio decreased during the study period. A more detailed analysis in which economic growth was compared between regions in different phases of the DWO revealed that economic growth was largest in regions that are in the second to fourth phase of the DWO, called here the pre, early and mid-window phases.

Our interaction analysis showed that the effects of the DWO on economic growth are not everywhere the same. The positive associations between a lower dependency ratio and economic growth, as well as of a reduction of the dependency ratio and economic growth, are stronger in rural areas. This indicates that these areas can profit more of the DWO than more urban areas. Also, investments in education have the expected effect with a more effective DWO in areas with a higher educational level. Together, these finding suggest that rural areas, which have invested in reasonable educational facilities, have the highest propensity to reap the demographic dividend.

The positive effect of a reduction in the dependency ratio on economic growth is strengthened in regions with higher levels of development, in regions with good governance and in regions with lower levels of financial development. The first finding makes clear that for very poor regions it is more difficult to make use of the window, which sets sub-Saharan Africa at a disadvantage compared to LMICs in other regions. Regarding governance, corruption seems the decisive factor, with areas within countries with higher levels of corruption being less able to turn a decreasing dependency ratio into growth.

A low level of financial development, on the other hand, does not seem problematic for reaping the DWO. This might have to do with the way growth is measured: on the basis of household wealth instead of GDP. Whereas GDP growth might depend on business activities that require a well-developed financial infrastructure, this is less the case for increases in household wealth (as measured by the IWI). Our data show that in countries with weak financial institutions households are even better able to translate the extra income due to reduction of the number (and hence costs) of children into asset ownership and improved housing quality. This may have to do with a greater importance of informal social networks in these countries, including local savings and credit associations (Anderson \& Baland, 2002; Besley et al., 1993). There are indications that informal institutions may become less effective under stricter formal regulation (Williamson, 2009).

Important is also our finding that already in the second phase of the DWO, called prewindow phase, a significant increase in economic growth is observed. Hence, regions in an early phase of fertility reduction might already experience benefits in terms of economic growth. On the other hand, regions that are in the late window phase (with less than $20 \%$ under 15 and less than $15 \%$ over 65 ) seem to experience less advantages of their demographic situation than countries in an earlier phase. This might mean that in those countries 
growth chances already start to be affected by the growing number of elderly, and that the effect of the old-age dependency ratio on growth is relatively strong.

In terms of policy implications, we urge policymakers to invest in education and particularly so in rural areas. Control of corruption should be another important policy concern, as the positive effects of good governance that are observed are completely due to improvements made in its corruption dimension. Moreover, we find that investing in education during the DWO leads to a much lower demographic dividend than investing in education early on.

In conclusion, our paper contributes to the existing literature by analyzing the effect of the DWO at subnational level for a large sample of LMICs. Population age-structures matter for economic growth, not only at the national level but also for specific areas within countries. Additionally, our interaction analysis confirms that the relationship between demography and economic growth is not a simple one but depends to a substantial extent on characteristics of the context in which the changes are taking place. Consequently, the implementation of policies such as family planning, labor market policies and education policies should take the unique characteristics of a specific area into account.

Supplementary Information The online version contains supplementary material available at https:/doi. org/10.1007/s11205-021-02802-8.

Acknowledgements We gratefully acknowledge the comments and suggestions made by participants of the 8th African Population Conference held in Entebbe, Uganda in November 2019.

Funding Open Access funding provided by ETH Zurich. There was no project-specific funding.

Data Availability All data will be made available in case of acceptance.

\section{Declarations}

Conflict of interest The authors declare that they have no conflict of interest.

Open Access This article is licensed under a Creative Commons Attribution 4.0 International License, which permits use, sharing, adaptation, distribution and reproduction in any medium or format, as long as you give appropriate credit to the original author(s) and the source, provide a link to the Creative Commons licence, and indicate if changes were made. The images or other third party material in this article are included in the article's Creative Commons licence, unless indicated otherwise in a credit line to the material. If material is not included in the article's Creative Commons licence and your intended use is not permitted by statutory regulation or exceeds the permitted use, you will need to obtain permission directly from the copyright holder. To view a copy of this licence, visit http://creativecommons.org/licenses/by/4.0/.

\section{References}

Aaronson, D., Dehejia, R., Jordan, A., Pop-Eleches, C., Samii, C., \& Schulze, K. (2021). The effect of fertility on mothers' labor supply over the last two centuries. The Economic Journal, 131(633), 1-32. https://doi.org/10.1093/ej/ueaa100

Allison, P. D. (2002). Missing data. Sage Publications.

Anderson, S., \& Baland, J. M. (2002). The economics of roscas and intrahousehold resource allocation. The Quarterly Journal of Economics, 117(3), 963-995. https://doi.org/10.1162/003355302760193931.

Baerlocher, D., Parente, S., \& L., and Rios-Neto, E. . (2019). Economic effects of demographic dividend in Brazilian regions. The Journal of the Economics of Ageing. https://doi.org/10.1016/j.jeoa.2019.100198

Barro, R. J. (1991). Economic growth in a cross section of countries. The Quarterly Journal of Economics, 106(2), 407-443. https://doi.org/10.2307/2937943 
Besley, T., Coate, S., \& Loury, G. (1993). The economics of rotating savings and credit associations. The American Economic Review, 792-810. https://www.jstor.org/stable/2117579.

Bloom, D., \& Canning, D. (2008). Global demographic change: Dimensions and economic significance. Population and Development Review, 34, 17-51.

Bloom, D., Canning, D., Fink, G., \& Finlay, J. E. (2009). Fertility, female labor force participation, and the demographic dividend. Journal of Economic Growth, 14(2), 79-101. https://doi.org/10.1007/ s10887-009-9039-9

Bloom, D., Canning, D., \& Sevilla, J. (2003). The demographic dividend: A new perspective on the economic consequences of population change. RAND Corporation. https://doi.org/10.7249/MR1274

Bloom, D., Kuhn, M., \& Prettner, K. (2017). Africa's prospects for enjoying a demographic dividend. Journal of Demographic Economics, 83(1), 63-76. https://doi.org/10.1017/dem.2016.19

Bloom, D., \& Williamson, J. G. (1998). Demographic transitions and economic miracles in emerging Asia. The World Bank Economic Review, 12(3), 419-455. https://doi.org/10.1093/wber/12.3.419

Canning, D., Raja, S., and Yazbeck, A. (Eds.). (2015). Africa's demographic transition: Dividend or disaster? The World Bank.

Collier, P., \& Dollar, D. (2001). Can the world cut poverty in half? How policy reform and effective aid can meet international development goals. World Development, 29(11), 1787-1802. https://doi.org/10. 1016/S0305-750X(01)00076-6

Crespo Cuaresma, J., Lutz, W., \& Sanderson, W. (2014). Is the demographic dividend an education dividend? Demography, 51(1), 299-315. https://doi.org/10.1007/s13524-013-0245-X

Cristia, J. P. (2008). The effect of a first child on female labor supply: Evidence from women seeking fertility services. Journal of Human Resources, 43(3), 487-510. https://doi.org/10.3368/jhr.43.3.487

Dreher, A. (2006). Does globalization affect growth? Evidence from a new index of globalization. Applied Economics, 38(10), 1091-1110. https://doi.org/10.1080/00036840500392078

Dreher, A., Gaston, N., and Martens, P. (2008). Measuring Globalization: Gauging its Consequences. Springer.

Easterlin, R. A. (1971). Does human fertility adjust to the environment? The American Economic Review, 61(2), 399-407.

Eloundou-Enyegue, P. M., Giroux, S., \& Tenikue, M. (2017). African transitions and fertility inequality: A demographic Kuznets hypothesis. Population and Development Review, 43, 59-83. https://doi.org/10. 1111/padr.12034

Eloundou-Enyegue, P. M., and Hirschl, N. (2017). Fertility transitions and schooling dividends in Sub-Saharan Africa: The experience of Vanguard Countries. In H. Groth and J. F. May (Eds.), Africa's Population: In Search of a Demographic Dividend (pp. 101-111). Springer International Publishing. https:// doi.org/10.1007/978-3-319-46889-1_7

Groth, H., and May, J. F. (Eds.). (2017). Africa's Population: In Search of a Demographic Dividend (1st ed. 2017). Springer International Publishing: Imprint: Springer. https://doi.org/10.1007/ 978-3-319-46889-1

Gygli, S., Haelg, F., Potrafke, N., \& Sturm, J.-E. (2019). The KOF globalisation index-revisited. The Review of International Organizations, 14, 543-574. https://doi.org/10.1007/s11558-019-09357-X

Huisman, J., \& Smits, J. (2009). Effects of household-and district-level factors on primary school enrollment in 30 developing countries. World Development, 37(1), 179-193. https://doi.org/10.1016/j.world dev.2008.01.007.

Jimenez, E., and Pate, M. A. (2017). Reaping a demographic dividend in Africa's largest Country: Nigeria. In H. Groth and J. F. May (Eds.), Africa's Population: In Search of a Demographic Dividend (pp. 33-51). Springer International Publishing. https://doi.org/10.1007/978-3-319-46889-1_3

Kaufmann, D., Kraay, A., \& Mastruzzi, M. (2011). The worldwide governance indicators: Methodology and analytical issues. Hague Journal on the Rule of Law, 3(2), 220-246. https://doi.org/10.1017/S1876 404511200046

Kelley, A. C., \& Schmidt, R. M. (2005). Evolution of recent economic-demographic modeling: A synthesis. Journal of Population Economics, 18, 275-300. https://doi.org/10.1007/s00148-005-0222-9

Kumar, U. (2013). India's demographic transition: Boon or bane? Asia \& the Pacific Policy Studies, 1(1), 186203. https://doi.org/10.1002/app5.9

Lee, E. S. (1966). A theory of migration. Demography, 3(1), 47. https://doi.org/10.2307/2060063

Loayza, N. V., Rancière, R., Servén, L., \& Ventura, J. (2007). Macroeconomic volatility and welfare in developing countries: An introduction. The World Bank Economic Review, 21(3), 343-357. https://doi.org/10. 1093/wber/lhm017

Preston, S. H., Himes, C., \& Eggers, M. (1989). Demographic conditions responsible for population aging. Demography, 26(4), 691. https://doi.org/10.2307/2061266 
Radelet, S., Sachs, J., \& Jong-Wha, L. (2001). The determinants and prospects of economic growth in Asia. International Economic Journal, 15(3), 1-29. https://doi.org/10.1080/10168730100000041

Sander, N., and Charles-Edwards, E. (2017). Internal and International Migration. In H. Groth and J. F. May (Eds.), Africa's Population: In Search of a Demographic Dividend (pp. 333-349). Springer International Publishing. https://doi.org/10.1007/978-3-319-46889-1_21

Shapiro, D., Tambashe, B. O., and Romaniuk, A. (2017). The Third Biggest African Country: The Democratic Republic of the Congo. In H. Groth and J. F. May (Eds.), Africa's Population: In Search of a Demographic Dividend (pp. 71-86). Springer International Publishing. https://doi.org/10.1007/978-3-319-46889-1_5

Smits, J. (2016). GDL Area Database. Sub-national development indicators for research and policy-making. GDL Working Paper, 16-101.

Smits, J., \& Steendijk, R. (2015). The international wealth index (IWI). Social Indicators Research, 122, 65-85. https://doi.org/10.1007/s11205-014-0683-X

Svirydzenka, K. (2016). Introducing a New Broad-Based Index of Financial Development. IMF Working Paper No. 16/5, 1-44.

Turbat, V. (2017). Economic Growth and Public and Private Investments. In H. Groth and J. F. May (Eds.), Africa's Population: In Search of a Demographic Dividend (pp. 353-365). Springer International Publishing. https://doi.org/10.1007/978-3-319-46889-1_22

United Nations. (2004). World Population to 2300. United Nations Population Division.

United Nations. (2018). World Urbanization Prospects: The 2018 Revision. Department of Economic and Social Affairs, Population Division.

Wei, Z., \& Hao, R. (2010). Demographic structure and economic growth: Evidence from China. Journal of Comparative Economics, 38(4), 472-491. https://doi.org/10.1016/j.jce.2010.08.002

Williamson, C. R. (2009). Informal institutions rule: Institutional arrangements and economic performance. Public Choice, 139(3-4), 371-387. https://doi.org/10.1007/s11127-009-9399-x

Williamson, J. G. (2013). Demographic dividends revisited. Asian Development Review, 30(2), 1-25.

Wooldridge, J. M. (2013). Introductory econometrics: A modern approach (5th ed). South-Western Cengage Learning.

World Bank. (2021). World Development Indicators. Inflation, consumer prices (annual \%). https://databank. worldbank.org/home.aspx

Zuber, A., Blickenstorfer, C., and Groth, H. (2017). Governance, Transparency, and the Rule of Law. In H. Groth and J. F. May (Eds.), Africa's Population: In Search of a Demographic Dividend (pp. 367-384). Springer International Publishing. https://doi.org/10.1007/978-3-319-46889-1_23

Publisher's Note Springer Nature remains neutral with regard to jurisdictional claims in published maps and institutional affiliations. 